\title{
Comparing Genotypic and Phenotypic Variation of Selfed and Outcrossed Progeny of Hemp
}

\author{
Lauren E. Kurtz, Jonathan D. Mahoney, Mark H. Brand, \\ and Jessica D. Lubell-Brand \\ Department of Plant Science and Landscape Architecture, University of \\ Connecticut, Storrs, CT 06269-4067
}

Additional index words. cannabidiol (CBD), Cannabis sativa, feminized seed, inbreeding, silver thiosulfate

\begin{abstract}
Feminized hemp seed producers often use selfing to maintain a strain name; however, selfing may lead to inferior plants for cannabidiol (CBD) production. Using three different hemp strains as parents [Candida (CD-1), Dinamed CBD, and Abacus], two outcrosses [Candida (CD-1) $\times$ Abacus and Dinamed CBD $\times$ Candida $(C D-1)]$ and one self-cross [Candida (CD-1) $\times$ Candida (CD-1)] were conducted to produce feminized seed. Progeny from the self-cross were significantly smaller and had less yield than outcrossed progeny. Selfed progeny were variegated and highly variable for total dry weight and floral dry weight. Discriminant analysis of principal components (DAPC) using amplified fragment length polymorphism (AFLP) separated the three progeny populations and showed that outcrossed populations clustered closer to the maternal parent, possibly the result of a maternal effect. Analysis of molecular variance (AMOVA) indicated that most variation $(\mathbf{7 4 . 5 \%})$ was within populations, because the progeny from all three populations are half-siblings of each other. The selfed progeny population had lower expected heterozygosity $\left(\mathrm{H}_{\mathrm{e}}=\mathbf{0 . 0 8 5}\right)$ than each of the outcrossed progeny populations $\left(\mathrm{H}_{\mathrm{e}} \approx 0.10\right)$. These results suggest that selfed progeny may demonstrate inbreeding depression resulting from enhanced expression of homozygous recessive traits. It may be beneficial for feminized seed producers to use outcrossing instead of selfing to generate feminized seed for CBD production.
\end{abstract}

Cannabis sativa is a diploid, dioecious species and is commonly referred to as hemp or marijuana, depending on the amount of tetrahydrocannabinol (THC) produced by the plant. Female plants are preferred for the production of cannabinoids, such as THC and $\mathrm{CBD}$, because they produce significantly more cannabinoids than male plants. Feminized seed is desirable for CBD hemp production. Feminized seed is produced when female plants are pollinated using pollen from masculinized female plants (Mohan Ram and Sett, 1982). Masculinization of female plants can be accomplished using foliar sprays of silver thiosulfate (Lubell and Brand, 2018). Based on statements from hemp growers and extension educators, seed producers may implement selfing (crossing a single genotype with itself) to generate feminized seed. When producing feminized seed, growers will vegetatively propagate a selected female genotype, and masculinize some percentage of the potted clones to generate female pollen, which is then used

Received for publication 8 Apr. 2020. Accepted for publication 21 May 2020.

Published online 22 June 2020.

J.D.L.-B. is the corresponding author. E-mail: Jessica.lubell@uconn.edu.

This is an open access article distributed under the CC BY-NC-ND license (https://creativecommons. org/licenses/by-nc-nd/4.0/).
Dinamed CBD $\times$ Candida $(\mathrm{CD}-1)$, and Candida $(\mathrm{CD}-1) \times$ Abacus. One plant each of Abacus and Candida (CD-1) were masculinized using foliar sprays of a 3-mm concentration of silver thiosulfate according to the procedure outlined by Lubell and Brand (2018) to generate feminized pollen for crosses. Abacus and Candida (CD-1) plants were masculinized to produce feminized pollen for crosses at different times to eliminate the risk of pollen contamination, because hemp pollen can spread between greenhouses as a result of venting. The Candida $(\mathrm{CD}-1) \times$ Abacus cross was conducted in Dec. 2018, and the Candida (CD-1) $\times$ Candida (CD-1) and Dinamed CBD $\times$ Candida $(\mathrm{CD}-1)$ crosses were conducted in Feb. 2019. Parent plants were well established in 3-gal containers when pollination was conducted.

Progeny growth. Before sowing, 20 feminized seeds of Candida (CD-1) $\times$ Candida $(\mathrm{CD}-1)$ and Dinamed CBD $\times$ Candida $(C D-$ 1), and 15 feminized seeds of Candida (CD1) $\times$ Abacus were soaked in water for $24 \mathrm{~h}$ and then transferred to $100 \times 15-\mathrm{mm}$ petri dishes lined with moistened filter paper (Whatman no. 4; Whatman, Maidstone, UK), where they were held for another 24 h. After this treatment, radicals had emerged from 1 to $5 \mathrm{~mm}$ and seeds were sown to a depth of 6 to $8 \mathrm{~mm}$ in 50-cell plug trays using a peatmoss-based seed starting mix (Promix BK25-V; Premier Tech Horticulture, Quakertown, PA). After 7 d, 12 seedlings of each cross were potted into $307-\mathrm{mL}$ square pots containing a peat-based grower mix (Promix BK25; Premier Tech Horticulture). Containers were top-dressed with controlled release fertilizer (Osmocote Plus 15N-3.9P10K 5- to 6-month formulation; Everris NA, Dublin, $\mathrm{OH}$ ) at $4 \mathrm{~g} /$ container. Plants were grown in the greenhouse with set points of $21 / 17{ }^{\circ} \mathrm{C}$ day/night under long-day conditions $(18 \mathrm{~h})$ for $14 \mathrm{~d}$, and then were potted into 2-gal pots containing the same medium described earlier. Pots were top-dressed with an additional $32 \mathrm{~g}$ controlled release fertilizer as described. During long-day conditions (vegetative stage), plants received a soluble fertilizer (Peters 20N-8.7P-6.6K; Scotts, Marysville, $\mathrm{OH}$ ) providing $100 \mathrm{ppm}$ nitrogen (N) at every irrigation as needed.

At $33 \mathrm{~d}$ after sowing, plants were provided short days (12 h) using blackout curtains to induce flowering after vegetative growth. During the flowering stage, plants received a soluble fertilizer (Peters $15 \mathrm{~N}-12.9 \mathrm{P}-$ $12.5 \mathrm{~K}$, Scotts) providing $100 \mathrm{ppm} \mathrm{N}$ at a daily rate of $2 \mathrm{~L}$ for plants of Dinamed $\mathrm{CBD} \times$ Candida (CD-1) and Candida (CD-1) $\times$ Abacus, and $1 \mathrm{~L}$ for plants of Candida (CD-1) $\times$ Candida (CD-1). Candida (CD-1) $\times$ Candida (CD-1) plants received less fertigation because plants were smaller and did not require as much water. Water was provided once every $7 \mathrm{~d}$ to flush accumulated salts. Plants were arranged in a completely random design throughout their growth. Plants were grown under short days for $40 \mathrm{~d}$ and then were harvested by cutting the plants at the base of the stem. Plant material was laid flat in metal 
Table 1. Nomenclature, parentage, and plant description for the three parental hemp strains: Abacus, Candida (CD-1) and Dinamed CBD.

\begin{tabular}{|c|c|c|c|c|c|}
\hline Strain & Parentage $^{z}$ & Origin & CBD (\%) & Plant ht $(\mathrm{cm})$ & Plant description \\
\hline Abacus & $\begin{array}{l}(\mathrm{OG} \times \text { Purple Urkle }) \times \text { High } \\
\mathrm{CBD} \text { industrial hemp }\end{array}$ & Clonal cuttings & 15 & $75-80$ & $\begin{array}{l}\text { Upright, spreading habit; dark-green leaves } \\
\text { and purple stems; high CBD industrial hemp }\end{array}$ \\
\hline Candida (CD-1) & ACDC $\times$ Harlequin & Feminized seed & 6 & $50-55$ & $\begin{array}{l}\text { Compact, densely branched habit; fine-texture } \\
\text { plant with narrow leaflets }\end{array}$ \\
\hline Dinamed CBD & Dancehall $\times$ Dancehall & Feminized seed & 9 & $50-55$ & $\begin{array}{l}\text { Compact, densely branched habit; stout stems } \\
\text { and dark-green leaves with broad leaflets }\end{array}$ \\
\hline
\end{tabular}

Information adapted from Blacklands Botanicals (2019), Seedsman (2020), and Dinafem Seeds (2020).

$\mathrm{CBD}=$ cannabidiol

Table 2. Vegetative and floral growth and yield for the progeny from three crosses: Candida (CD-1) $\times$ Candida $(\mathrm{CD}-1)$, Dinamed CBD $\times$ Candida $(\mathrm{CD}-1)$, and Candida (CD-1) $\times$ Abacus.

\begin{tabular}{|c|c|c|c|c|c|c|c|}
\hline & $\mathrm{n}$ & $\begin{array}{l}\text { Dinamed CBD } \times \\
\text { Candida }(C D-1)\end{array}$ & $\mathrm{CV}$ & Candida $(\mathrm{CD}-1) \times$ Abacus & $\mathrm{CV}$ & $\begin{array}{c}\text { Candida }(\mathrm{CD}-1) \times \\
\text { Candida }(\mathrm{CD}-1)\end{array}$ & $\mathrm{CV}$ \\
\hline \multicolumn{8}{|l|}{ Vegetative (days 1-33) } \\
\hline Height at day $7(\mathrm{~cm})$ & 12 & $6.3 \mathrm{a}^{\mathrm{z}}$ & 13.1 & $5.8 \mathrm{a}$ & 33.1 & $3.6 \mathrm{~b}$ & 19.6 \\
\hline Height at day $30(\mathrm{~cm})$ & 12 & $37.8 \mathrm{a}$ & 9.4 & $40.3 \mathrm{a}$ & 20.6 & $24.0 \mathrm{~b}$ & 11.5 \\
\hline No. of nodes & 12 & $9.3 \mathrm{a}$ & 5.3 & $9.5 \mathrm{a}$ & 12.3 & $8.0 \mathrm{~b}$ & 0 \\
\hline Internode length $(\mathrm{cm})^{\mathrm{y}}$ & 12 & $4.1 \mathrm{a}$ & 9.1 & $4.2 \mathrm{a}$ & 15.1 & $3.0 \mathrm{~b}$ & 11.5 \\
\hline Leaf area $\left(\mathrm{cm}^{2}\right)$ & 12 & $51.4 \mathrm{a}$ & 7.4 & $53.4 \mathrm{a}$ & 27.7 & $20.9 \mathrm{~b}$ & 11.4 \\
\hline \multicolumn{8}{|l|}{ Floral (days 34-74) } \\
\hline Height at day $47(\mathrm{~cm})$ & 12 & $72.8 \mathrm{~b}$ & 9.4 & $89.3 \mathrm{a}$ & 22.1 & $45.2 \mathrm{c}$ & 10.3 \\
\hline Total dry weight $(\mathrm{g})$ & 12 & $190.3 \mathrm{a}$ & 22.2 & $195.0 \mathrm{a}$ & 32.2 & $79.3 \mathrm{~b}$ & 58.4 \\
\hline Flower dry weight (g) & 12 & $101.9 \mathrm{a}$ & 25.8 & $101.9 \mathrm{a}$ & 33.9 & $37.3 \mathrm{~b}$ & 63.7 \\
\hline $\mathrm{CBD}(\%)$ & 8 & $8.4 \mathrm{~b}$ & 24.6 & $14.4 \mathrm{a}$ & 8.9 & $5.4 \mathrm{c}$ & 30.1 \\
\hline THC (\%) & 8 & $<0.1$ & & $<0.1$ & & $<0.1$ & \\
\hline
\end{tabular}

${ }^{\mathrm{z}}$ Mean separation within rows indicated by different letters, by Fisher's least significant difference at $P \leq 0.05$.

${ }^{y}$ Internode length was the quotient of height divided by the number of nodes.

$\mathrm{CBD}=$ cannabidiol; THC $=$ tetrahydrocannabinol.
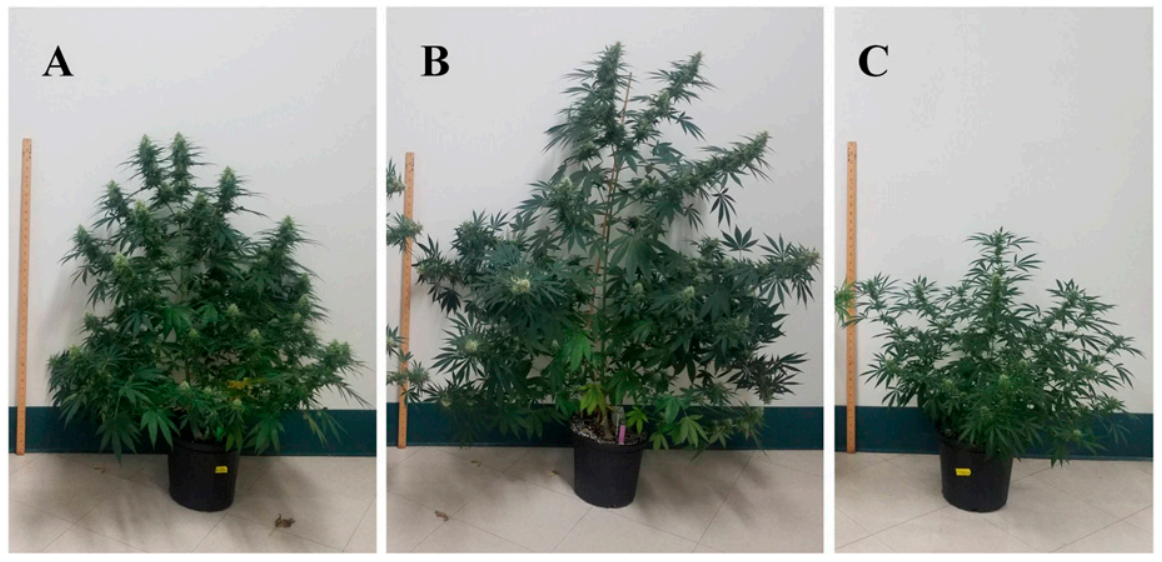

Fig. 1. Representative plants at day 74 of the study: (A) Dinamed CBD $\times$ Candida (CD-1), (B) Candida $(\mathrm{CD}-1) \times$ Abacus, and $(\mathrm{C})$ Candida $(\mathrm{CD}-1) \times$ Candida $(\mathrm{CD}-1)$.
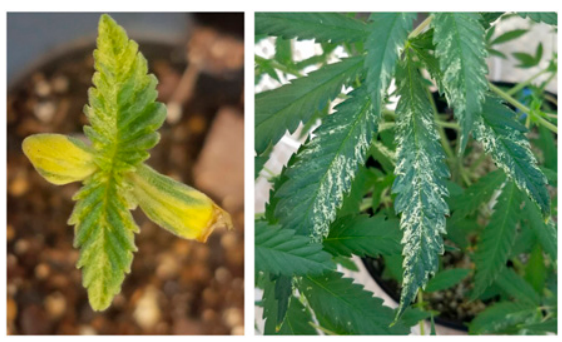

Fig. 2. Candida (CD-1) $\times$ Candida (CD-1) 6-d-old seedling and 33-d-old leaf showing variegation.

trays and allowed to dry for $14 \mathrm{~d}$ at 65 to $68^{\circ} \mathrm{F}$ in a laboratory of the Agricultural Biotechnology Laboratory Building at the University of Connecticut in Storrs, CT.
Data collection and statistical analysis. Germination rate was recorded for each cross $6 \mathrm{~d}$ after sowing. Plant height was measured on days 7, 30, and 47 after sowing. Number of nodes on the main stem was recorded on day 30. Internode length was calculated by dividing height by the number of nodes. On day 30 , leaf area was measured using a scanner (Epson Perfection V700; Epson America, Long Beach, CA) and ImageJ software (version 1.52a; National Institute of Health, Bethesda, MD) for four leaves per plant, sampled from randomly selected shoots at the fourth node back from the shoot tip, and then averaged. Total dry weight of stems, leaves, and inflorescences was measured for each plant. Inflorescences were separated from stems and leaves, and weighed.

For cannabinoid analysis, a 160 - to 200 mg subsample of dried inflorescence was used per plant. Eight plants per cross were analyzed. The subsample was ground using a mortar and pestle and combined with $40 \mathrm{~mL}$ isopropyl alcohol in a $50-\mathrm{mL}$ conical tube. Samples were vortexed for $2 \mathrm{~min}$, sonicated for $30 \mathrm{~min}$, and spun down. The extraction solution was filtered through a $0.22-\mu \mathrm{m}$ filter (PTFE-L Syringe Filter; Simsii, Irvine, CA) and subjected to high-performance liquid chromatography analysis (1260 Infinity; Agilent Technologies Inc., Santa Clara, CA). The following standards were used as calibrants: cannabigerol, cannabigerolic acid, CBD, cannabidolic acid, cannabinol, cannabichrome, $\Delta 9$-THC, $\triangle 8$-THC, and THC acid (Absolute Standards Inc., Hamden, CT).

Data were subjected to analysis of variance (Proc GLM) and mean separation with Fisher's least significance difference test $(P$ $\leq 0.05$ ) using SAS (version 9.4; SAS Institute, Cary, NC). For variables that did not exhibit a normal distribution, square root transformation was performed. Table 2 provides the actual means and transformed letters.

DNA extraction and AFLP. Actively growing shoot tips were collected from the three parent plants and 12 progeny of each cross. Samples were stored in a $-80{ }^{\circ} \mathrm{C}$ freezer until DNA extraction. Genomic DNA was extracted and AFLP reactions were carried out following the protocol outlined in Mahoney et al. (2019). Quality and concentration of extracted DNA were measured using a spectrophotometer (NanoDrop1000; Thermo Scientific, Willington, DE). The AFLP steps included restriction digestion and adaptor ligation, preselective amplification, and selective amplification. Preselective primers had one selective 
nucleotide (EcoRI-A + MseI-C). The following six primer combinations were used for selective amplification: EcoRI-ACT + MseI-CAT, EcoRI-ACT + MseI-CTG, EcoRI-AGG + MseI-CTC, EcoRI-AGG + MseI-CAT, EcoRIAGG + MseI-CAC, and EcoRI-ACC + MseI-CAC.

AFLP fragment files were processed into binary matrices using GeneMarker (version 1.95; SoftGenetics, State College, PA). Peaks were scored with a 1 for present and a 0 for absent using automatic settings. Peaks were visually inspected to ensure accurate scoring. The data frame was converted into a genind object using the df2genind command with the $\mathrm{R}$ package adegenet 2.1.1 (Jombart, 2008). DAPC (Jombart et al., 2010) was conducted using a multivariate clustering method with the $\mathrm{R}$ package adegenet 2.1.1 (Jombart, 2008). Five principal components were retained to produce the DAPC, and the clusters were plotted on the first and second linear discriminants. Expected $\mathrm{H}_{e}$ was calculated based off of Nei's $\mathrm{H}_{\mathrm{e}}$ (Nei, 1978) using the $\mathrm{R}$ package poppr 2.8.3 (Kamvar et al., 2014). AMOVA was determined using the poppr.amova function in the $\mathrm{R}$ package poppr 2.8.3 (Kamvar et al., 2014).

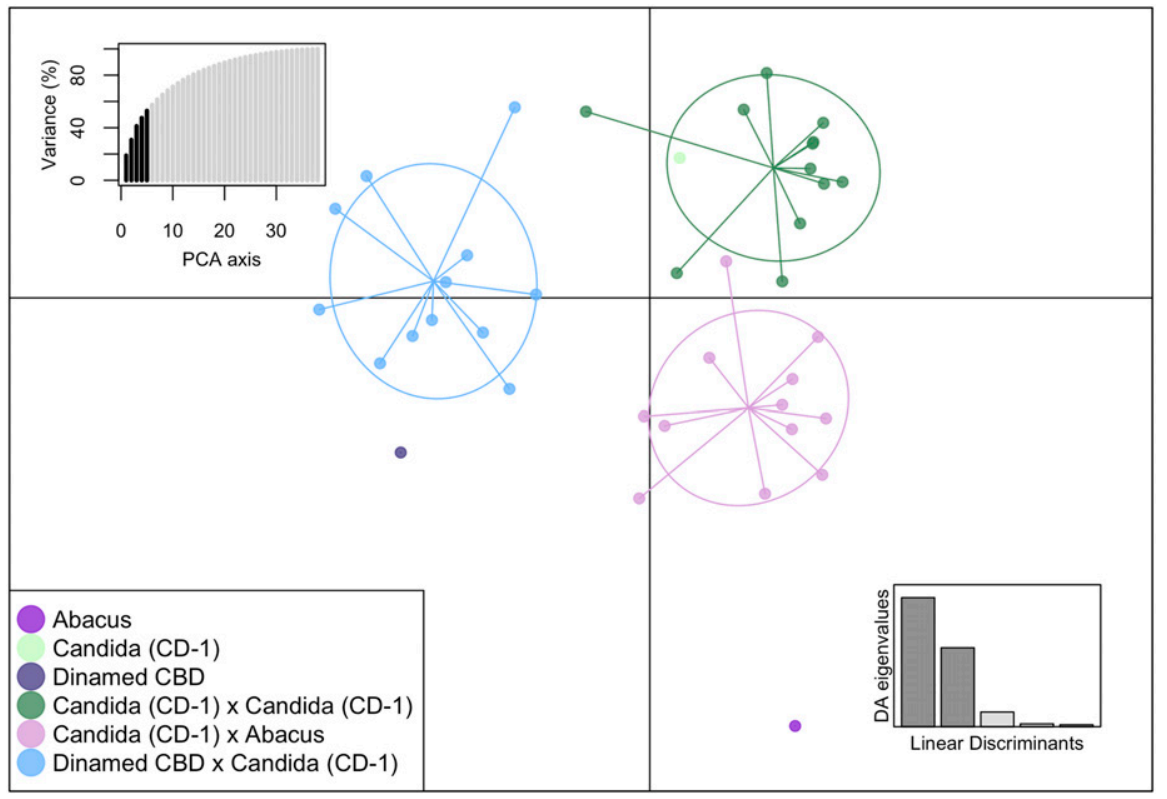

Fig. 3. Discriminant analysis of principal components for 12 progeny per cross [Dinamed CBD $\times$ Candida $(\mathrm{CD}-1)$, Candida $(\mathrm{CD}-1) \times$ Candida $(\mathrm{CD}-1)$, and Candida $(\mathrm{CD}-1) \times$ Abacus $]$ and the three parent genotypes: Abacus, Candida (CD-1), and Dinamed CBD. Dots represent different individuals. Insert graphs display principal components analysis (PCA) variance for the retained five principal components and DA eigenvalues for the first two linear discriminants.
Selfed progeny were about the same size as their parent based on our experience growing a crop of Candida (CD-1). Cuttingderived plants of Candida (CD-1), produced under similar duration vegetative and floral growth periods, reached $57 \mathrm{~cm}$ and an accumulated dry weight of $78 \mathrm{~g}(\mathrm{n}=15$; data not shown). From our familiarity with growing the parents, we concluded that Dinamed CBD $\times$ Candida (CD-1) hybrids were larger than both parents, and Candida $(\mathrm{CD}-1) \times$ Abacus hybrids were larger than the maternal parent and of similar size to slightly larger than the paternal parent. Small (1972) observed hybrid $C$. sativa plants were larger and exhibited hybrid vigor compared with plants grown from parental seed stock.

All selfed progeny exhibited leaf variegation, which is known to be a recessive genetic trait in higher plants (Sakamoto, 2003). The parent Candida (CD-1) plant was not variegated, so the observed variegation likely does not result from a single homozygous recessive locus. Variegation was first evident at the cotyledon growth stage, and it persisted through day 35 of the study for most plants; three plants had variegated leaves until the end of the study (Fig. 2). The phenotypic variation among selfed progeny for total dry weight $(\mathrm{CV}=58 \%)$ and floral dry weight $(\mathrm{CV}=$ $64 \%$ ) was two to three times greater than for outcrossed progeny (Table 2). Jones and Singleton (1940) observed leaf variegation on strawberry plants self-fertilized for three consecutive generations, and increased phenotypic variation and more extreme expression of traits were found for inbred strawberries. Inbred progeny of Daphnia obtusa demonstrated increased variation in growth compared with outbred progeny (Innes, 1989). The increased phenotypic variation found among our selfed hemp progeny may be attributable to the enhanced expression of different recessive alleles upon selfing (Deng, 1997; Stebbins, 1957).

AFLP using six primer pairs yielded 205 total bands, of which $52 \%$ were polymorphic. DAPC identified three distinct progeny clusters representing the crosses Candida (CD-1) $\times$ Abacus, Candida $(\mathrm{CD}-1) \times$ Candida $(\mathrm{CD}-1)$, and Dinamed CBD $\times$ Candida $(\mathrm{CD}-1$; Fig. 3). Outcrossed populations clustered closer to the maternal parent than the pollen parent, possibly resulting from a maternal effect (Roach and Wulff, 1987). The two progeny populations for which Candida (CD1 ) was the maternal parent, Candida $(\mathrm{CD}-1) \times$ Candida (CD-1) and Candida (CD-1) $\times$

Table 3. Number of bands, polymorphic bands, percent polymorphic bands, and expected heterozygosity $\left(\mathrm{H}_{\mathrm{e}}\right)$ based on Nei's gene diversity for the three hemp progeny groups [Candida $(\mathrm{CD}-1) \times$ Candida $(\mathrm{CD}-1)$, Dinamed CBD $\times$ Candida $(\mathrm{CD}-1)$, and Candida $(\mathrm{CD}-1) \times$ Abacus] and number of bands for the three parents: Abacus, Candida (CD-1), and Dinamed CBD.

\begin{tabular}{lcccr}
\hline & $\mathrm{n}$ & No. of bands & No. of polymorphic bands & Polymorphic bands (\%) \\
\hline Abacus & 1 & 160 & & $\mathrm{H}_{\mathrm{e}}$ \\
Candida (CD-1) & 1 & 170 & & \\
Dinamed CBD & 1 & 162 & 62 & 30.7 \\
Candida (CD-1) $\times$ Abacus & 12 & 202 & 60 & 29.9 \\
Candida (CD-1) $\times$ Candida (CD-1) & 12 & 201 & 58 & 0.104 \\
Dinamed CBD $\times$ Candida (CD-1) & 12 & 197 & 0.085 \\
\hline CBD & & & 0.101 \\
\hline
\end{tabular}

$\mathrm{CBD}=$ cannabidiol. 
Table 4. Analysis of molecular variance among and within progeny populations based on amplified fragment length polymorphism markers.

\begin{tabular}{lrcc}
\hline Source & df & Sum of squares & Variation (\%) \\
\hline Within progeny populations & 2 & 97.1 & 24.3 \\
Among progeny populations & 33 & 330.8 & 75.7 \\
Total & 35 & 427.8 & \\
\hline
\end{tabular}

Abacus clustered closer to each other than each did to the Dinamed CBD $\times$ Candida $(\mathrm{CD}-1)$ progeny population. The selfed population clustered closer to its parent than outcrossed populations did to their respective maternal parents. Datwyler and Weiblen (2006) differentiated progeny from four strains of $C$. sativa using principal components analysis of AFLP. They found that six inbred progeny of the hemp strain Carmen clustered more closely to each other than 13 progeny of Carmen from seedstock. Furthermore, they showed that inbred individuals of Carmen had reduced heterozygosity (0.135) than Carmen plants derived from seedstock of the strain Carmen (0.203). In our study, $\mathrm{H}_{\mathrm{e}}$ was 0.085 for the selfed population, 0.104 for Candida (CD-1) $\times$ Abacus, and 0.101 for Dinamed CBD $\times$ Candida (CD-1) (Table 3). Our findings suggest that the selfed hemp population is demonstrating early inbreeding. Levels of heterozygosity were less than levels detected by Datwyler and Weiblen (2006), possibly because the progeny from each of our crosses are half-siblings with the progeny from the other two respective crosses.

AMOVA showed within-progeny population variation was $74.5 \%$ and among-progeny population variation was $24.3 \%$ (Table 4 ). Variation within progeny populations was greater than that found by Datwyler and Weiblen (2006) using AFLP for progeny populations from four strains of $C$. sativa $(51.9 \%)$. This difference may be because all the progeny from our three crosses are half-siblings. Withinpopulation variation was greater than amongpopulation variation for $C$. sativa germplasm from Iran and Afghanistan (Soorni et al., 2017), and hemp accessions from Europe and Asia (Sawler et al., 2015).

Small (2015) reported that selfing in cannabis induces inbreeding depression. Our findings provide phenotypic and genotypic data to support this observation. Selfing, when maternal and pollen parents are the same genotype, to produce feminized seed can result in less vigorous plants and reduced yield. In addition, selfed plants have increased homozygosity and may display del- eterious recessive traits such as variegation. If we make the assumption that our Candida (CD-1) parental genotype was not the result of selfing by the seed producer, then our observations of variegation as early as the S1 compared with the S3 in strawberry (Jones and Singleton, 1940) suggests inbreeding may occur more rapidly in hemp than other crops. Based on our observations, crossing two different strains to maintain or increase heterozygosity could be a strategy to increase yields, and plants may be more uniform. If crossing within a strain is necessary for legal or economic reasons, then growers should consider using two different genotypes of the strain to produce feminized seed and maintain strain name. Hemp breeders may want to consider developing inbred parental lines to generate $F_{1}$ feminized seed, which could produce plants that exhibit improved crop uniformity and hybrid vigor. A limitation of this study was that only three strains and the progeny of three crosses were evaluated. More research is needed to evaluate a broader number of commercially available hemp strains and additional generations of selfing.

Agriculture Marketing Service. 2019. Establishment of a domestic hemp production program. 13 May 2020. <https://www.federalregister.gov/ $\mathrm{d} / 2019-23749>$

Blacklands Botanicals. 2020. Abacus. 2 Apr. 2020. $<$ https://blacklandsbotanicals.org/variety/ abacus $>$.

Datwyler, S.L. and G.D. Weiblen. 2006. Genetic L.) according to amplified fragment length polymorphisms. J. Forensic Sci. 51:371-375.

Deng, H.W. 1997. Increase in developmental instability upon inbreeding Daphnia. Heredity 78:182-189.

Dinafem Seeds. 2020. Dinamed CBD. 2 Apr. 2020. $<$ https://www.dinafem.org/en/dinamed-cbd/>.

Ellmer, M. and S. Andersson. 2004. Inbreeding depression in Nigella degenii (Ranunculaceae): Fitness components compared with morphological and phenological characters. Intl. J. Plant Sci. 165:1055-1061.

\section{Literature Cited} structure in hemp and marijuana (Cannabis sativa
Innes, D.J. 1989. Genetics of Daphnia obtusa: Genetic load and linkage analysis in a cyclical partenogen. Amer. Genet. Assn. 80(1):6-10.

Jombart, T. 2008. Adegenet: An R package for the multivariate analysis of genetic markers. Bioinformatics 24:1403-1405.

Jombart, T., S. Devillard, and F. Balloux. 2010. Discriminant analysis of principal components: A new method for the analysis of genetically structured populations. BMC Genet. 11:94.

Jones, D.F. and W.R. Singleton. 1940. The improvement of naturally cross-pollinated plants by selection in self-fertilized lines. Conn. Agr. Expt. Sta. 435:329-347.

Kamvar, Z.N., J.F. Tabima, and N.J. Grünwald. 2014. poppr: An R package for genetic analysis of populations with clonal, partially clonal, and/or sexual reproduction. PeerJ 2:e281.

Lubell, J.D. and M.H. Brand. 2018. Foliar sprays of silver thiosulfate produce male flowers on female hemp plants. HortTechnology 28:1-5.

Mahoney, J.D., T.M. Hau, B.A. Connolly, and M.H. Brand. 2019. Sexual and apomictic seed reproduction in Aronia species with different ploidy levels. HortScience 54:642-646.

MH International. 2020. What makes our feminized hemp seed different? Cheyenne Mountain Seed Company. 25 Feb. 2020. <https:// cheyennemountainseedcompany.com/>.

Mohan Ram, H.Y. and R. Sett. 1982. Induction of fertile male flowers in genetically female $\mathrm{Can}$ nabis sativa plants by silver nitrate and silver thiosulphate anionic complex. Theor. Appl. Genet. 62:369-375.

Nei, M. 1978. Estimation of average heterozygosity and genetic distance from a small number of individuals. Genetics 89:583-590.

Roach, D.A. and R.D. Wulff. 1987. Maternal effects in plants. Annu. Rev. Ecol. Syst. 18:209-235.

Sakamoto, W. 2003. Leaf-variegated mutations and their responsible genes in Arabidopsis thaliana. Genes Genet. Syst. 78:1-9.

Sawler, J., J.M. Stout, K.M. Gardner, D. Hudson, J. Vidmar, L. Butler, J.E. Page, and S. Myles. 2015. The genetic structure of marijuana and hemp. PLoS One 10:e133292.

Seedsman. 2020. Candida (CD-1). 2 Apr. 2020. $<$ https://www.seedsman.com/en/candida-cd-1feminised-seeds $>$.

Small, E. 1972. Infertility and chromosomal uniformity in Cannabis. Can. J. Bot. 50:19471949.

Small, E. 2015. Evolution and classification of Cannabis sativa (marijuana, hemp) in relation to human utilization. Bot. Rev. 81:189-294.

Soorni, A., R. Fatahi, D.C. Haak, S.A. Salami, and A. Bombarely. 2017. Assessment of genetic diversity and population structure in Iranian cannabis germplasm. Sci. Rep. 7:15668.

Stebbins, L. 1957. Self fertilization and population variability in the higher plants. Amer. Nat. 91:337-354. 